\title{
EJEM \\ Econ.J.Emerg.Mark.

\section{The role of agricultural productivity in economic growth in middle-income countries: An empirical investigation}

\author{
Arif Eser Güzel*, Cemil Serhat Akin \\ Department of Economics, Hatay Mustafa Kemal University, Hatay, Turkey \\ *Corresponding author: arifeserguzel@mku.edu.tr
}

\section{Article Info \\ Article bistory \\ Received : 15 November 2020 \\ Accepted : 8 March 2021 \\ Published : 1 April 2021 \\ JEL Classification Code: C23, O11, Q10 \\ Autbor's email: \\ arifeserguzel@mku.edu.tr csakin@mku.edu.tr}

DOI: 10.20885/ejem.vol13.iss1.art2

\begin{abstract}
Purpose - This study investigates the role of agricultural productivity in economic growth in middle-income countries.

Methods - This study utilizes the data of 53 middle-income countries over the period 1991-2017 and provides robust estimations using second-generation panel data methods considering crosssectional dependency.

Findings - The estimation results of the Common Correlated Effects Mean Group (CCEMG), Dynamic-CCEMG, and biased-corrected form of Dynamic-CCEMG, suggest that agricultural productivity is the main engine of economic growth. Additional findings show that economic growth is positively associated with both physical capital and human capital. This paper does not find any significant relationship between trade openness and economic growth.

Implications - This study reveals that the industrialization process in middle-income countries to boost economic growth can be accelerated by implementing policies to increase productivity in the agricultural sector.

Originality - This study focuses on analyzing the effect of agricultural productivity neglected mainly in recent studies on economic growth. This paper develops a second-generation estimator that considers cross-sectional dependence.
\end{abstract}

Keywords - Economic growth, agricultural productivity, human capital, trade openness.

\section{Introduction}

The early literature of economic development has shown modern industrialization as the basic dynamic of economic growth, while the agricultural labor force was a source of cheap labor to feed industrialization. Agriculture is perhaps the only sector that produces output in the countries at the early stages of development, and in these countries, the majority of society is employed in the agricultural sector (Johnston \& Mellor, 1961). In the period when the economy is transforming, there are opinions that the workers in the agricultural sector are the primary source of industrial development. In his study, Lewis (1954) claimed that while the industrial sector was growing, the agricultural sector would be a source of labor with sufficiently low wages in his two-sector model. With this "unlimited" supply of labor, agriculture would be a source of capital formation because of accessing cheap labor and yet, lower production costs. He showed the hidden unemployment in the agricultural sector as a cause of this sectoral transition. According to the World Food and 
Agriculture Statistical Pocketbook published by FAO (Food and Agriculture Organization of the United Nations), the percentage share of agricultural value-added diminishes with the development of a country (FAO, 2018). This report supports the idea proposed by Arthur Lewis. With the development of industrial sectors, the share of agriculture in GDP goes down because of the migration of workers from agriculture to the industrial sector. In the report of FAO, it is also mentioned that in order to keep agriculture moving, agricultural productivity per-worker should be increased.

At the end of the twentieth century, the dominant view on development economics suggested that the share of agriculture in the economy would naturally diminish, and therefore there was no need for modernization in agriculture. While Lewis's (1954)model disregarded efforts to modernize agriculture, Hirschman's (1958) approach prioritized the development of the manufacturing industry due to linkage effects (Timmer, 2002). Besides, Prebisch (1950) argued that the increase in agricultural production would cause deterioration in terms of trade. These approaches, which emerged in development theories, have resulted in not paying the necessary attention to the modernization of agriculture and productivity increase. Although the share of agriculture in the overall economy is diminishing, modernization of agriculture and increasing agricultural productivity are important for achieving more output by fewer workers in the agricultural sector. There are significant differences between high, middle, and low-income countries in the context of per worker output in the agricultural sector. To illustrate this difference, a comparison is given in Table 1.

Table 1. A comparison of agricultural productivity between different income groups (2016)

\begin{tabular}{lcc}
\hline & $\begin{array}{c}\text { Agricultural value-added per worker } \\
\text { (constant 2010) }\end{array}$ & $\begin{array}{c}\text { Agricultural value-added } \\
(\% \text { gdp) }\end{array}$ \\
\cline { 2 - 3 } High-income & $36799 \$$ & 1.3 \\
Middle-income & $2990 \$$ & 15.7 \\
Low-income & $599 \$$ & 25.4 \\
\hline
\end{tabular}

Source: World Bank, World Development Indicators (2019).

According to Table 1, there is evidence supporting the view that the share of agriculture in the economy decreases as the level of income increases. However, the high-income countries' agricultural output per worker is much higher than middle and low-income countries. In lowincome countries, the agricultural sector accounts for $25 \%$ of national income, while in middleincome countries, $15.7 \%$ and high-income countries only 1.4\%. According to World Development Indicators (2019), middle-income countries produce $74 \%$ of world agricultural output. However, there are significant productivity differences between high and middle-income countries. An agricultural worker in a high-income country is about 12.3 times more productive than in middleincome countries. Such a productivity difference may be a result of the effort to increase productivity. According to a global assessment of world agricultural R\&D spending published by Beintema, Stads, Fuglie, and Heisey (2012), 51\% of public agricultural R\&D investments are made in high-income countries. Also, most of the private sector R\&D investments are made by companies in developed OECD countries. Despite the neoclassical point of view, efforts to modernize agriculture would contribute to economic growth by increasing productivity. These efforts are also important to provide enough food for the rising human population worldwide. Increasing the need for food together with the ever-increasing population requires a continuous increase in agricultural productivity (Mariyono, Kompas, \& Grafton, 2010).

In the context of agriculture's traditional role in economic growth, Johnston and Mellor (1961) suggested four more linkages in addition to agriculture's role in providing cheap labor to industrial sectors. The first is that the agricultural sector provides food for consumption. Rising domestic food supply provides high-calorie nutrition to the workers. Since production in developing countries is predominantly based on unskilled labor, continuity of food production is important in meeting the food needs of workers. It also leads to stability in food prices and facilitates access to food (Timmer, 1995). The second linkage they established is from agricultural 
exports to economic growth. In the early stages of development, agricultural exports can be an important instrument to increase foreign exchange earnings and revenue. Countries that have achieved comparative advantages with industrial production will prefer to import agricultural food products (Nicholls, 1964). Less developed countries do not have enough capital accumulation to have a comparative advantage over industrial products. Therefore, agricultural exports are the main sources of foreign exchange earnings. The third is the contribution to investments. Since most of the total production in underdeveloped countries is carried out in the agricultural sector, the development of the industrial sector depends on the contribution of the agricultural sector to capital formation. The fourth is that increasing incomes in the agricultural sector can increase the demand for industrial products and contribute to the expansion of the industrial sector with a wider market.

Besides linkages proposed by Johnston and Mellor (1961), Kuznets (1964) and Ghatak and Ingersent (1984) explained the contribution of agriculture in economic growth in four different ways that are similar to the Johnston and Mellor's but provide a classification. These four ways are product contribution, market contribution, factor contribution, and foreign exchange contribution. According to Khan, Jamshed, and Fatima (2020), product contribution refers to the growth of product per capita, while market contribution represents the rising demand for industrial inputs such as fertilizer, pesticide, farm machinery, etc. Factor contribution refers to the shift of labor in the agricultural sector to non-agricultural sectors. Since the increase in productivity resulting from the increase in the use of technology in agriculture will provide higher output with less labor and capital use, these factors are employed in industry instead of agriculture. Finally, foreign exchange contribution is the contribution of agricultural exports to countries' foreign exchange earnings. In addition to its positive impact, agriculture may retard economic growth. Educational demands of agricultural workers are generally lower than those in trade, industry, and service sectors (Gylfason, 2000). Increasing the share of agriculture in the economy may lead to a decrease in overall human capital formation. Besides, the allocation of the labor force to the industrial sector may be higher in an economy with a less productive agricultural sector (Matsuyama, 1992). The allocation of more resources to the industrial sector can lead to faster economic growth.

In addition to theoretical discussions, there are several empirical studies in the previous literature. Hwa (1988) provided evidence of the contribution of agriculture to economic growth. Cross-sectional data of 87 countries covering the period 1960s and 1970s were used in this study. Cross-section regression results show that agricultural growth has a significant positive effect on overall economic growth. Yao (2000) concluded that agriculture is one of the driving forces of Chinese economic growth, supporting Hwa's (1988) evidence. The author also argued that biased policies against agriculture weaken the contribution of agriculture to economic growth. Irz, Lin, Thirtle, and Wiggins (2001) found a significant effect of agricultural productivity growth on rural poverty and human development. According to the results, rising agricultural productivity reduces poverty and increases human development. Gollin, Parente, and Rogerson (2002) provided panel data evidence using the data from 62 developing countries. The author concluded that agricultural productivity has a positive impact on economic growth. The movement of labor from agriculture to non-agricultural sectors also improves economic growth. According to this result, the allocation of the labor force to the industrial sector with an increase in per-worker agricultural productivity is effective in the economic development process. As opposed to this, Gardner (2005) found no causality between agriculture and overall economic growth. Following this study, Tiffin and Irz (2006) investigated the relationship between agricultural value-added and economic growth with a panel of 85 countries.

According to Granger causality results, there is unidirectional causality from agriculture to economic growth. Another study investigating the causality between agriculture and economic growth is proposed by Katırcioğlu (2006). He used annual data for North Cyprus in the period 1975-2002. The results indicate that there is bidirectional causality between agriculture and economic growth. While some studies have investigated the direct impact of agriculture on growth, while others have investigated the impact on non-agricultural sectors. Timmer (2002) found a significant positive impact of agricultural GDP growth on non-agricultural GDP growth. In his 
study, a panel of 70 countries was used, covering the five-year averages of the period 1960-1985. Bravo-Ortega and Lederman (2005) revisited the analysis of Timmer (2002) and concluded that was supporting Timmer's study. They used a wider panel data set than Timmer, covering five-year averages 1960-2000 with different agricultural growth definitions.

According to pooled OLS and fixed effects estimation results, non-agricultural growth is positively associated with agricultural growth. Chebbi (2010) examined the cointegration and causality between the agricultural and non-agricultural sectors in Tunisia. Cointegration results show a long-run relationship between agricultural GDP, real GDP of manufacturing and nonmanufacturing industries, tourism and transportation, and commerce and services sectors. Also, agricultural growth causes growth in the agro-food industry. Oyakhilomen and Zibah (2014) found a significant positive relationship between agricultural output and economic growth in Nigeria utilizing time-series data covering 1970-2011. Awokuse and Xie (2015) also examined the cointegration and causality between agriculture and economic growth. They used annual data for 9 developing and transition economies covering the period 1980-2011. The results obtained from the ARDL model established to analyze cointegration show a significant long-run relationship between agriculture and economic growth for all countries included in the model. Contemporaneous causality results obtained from dynamic acyclic graphs (DAGs) show a significant causality from GDP to agriculture in Chile, Mexico, Kenya, and South Africa. The causality from agriculture to GDP is significant in China, Indonesia, Thailand, and Cameroon. In Brazil, no significant causal relationship was found in their study. Sertoglu, Ugural, and Bekun (2017) also investigated the agriculture-economic growth nexus in Nigeria. Their time-series analysis is covering the period 1981-2013. They came to the same conclusion as Oyakhilomen and Zibah (2014). In their recent study, Khan et al. (2020) found that the agricultural sector positively impacts other sectors' economic growth in West Bengal. They concluded a long-run causality between the agricultural and industrial sectors, the service sector, and overall economic growth.

This study aims to investigate the role of agricultural productivity in economic growth in middle-income countries. Agriculture has an important place in the production and employment of middle-income countries. However, these countries are behind high-income countries in terms of agricultural productivity. According to Mariyono (2019), the widespread use of technology in agriculture and increased productivity are important for economic growth and rural development in emerging economies. However, it is observed that the effects of agricultural productivity are mostly neglected in recent studies on economic growth. In addition to previous empirical researches, this study provides second-generation panel data estimations. The empirical works in previous literature consist of traditional estimation methods called first-generation tests. In the analysis of panel data, the estimators considering cross-sectional dependence are called the secondgeneration estimators. Cross-sectional dependency simply refers to the situation when the shock that occurs in one country affects other countries as well. The source of this problem encountered in panel data analysis is the economic, financial, and political integration among countries (Menyah, Nazlioglu, \& Wolde-Rufael, 2014).

The assumption of cross-sectional independence is hard to satisfy because of the high level of economic integration among countries. İnoring this effect may lead to misleading inferences (Chudik \& Pesaran, 2013; De Hoyos \& Sarafidis, 2006). According to Awokuse and Xie(2015) and Tsakok and Gardner (2007), previous studies in the agricultural sector's contribution to economic growth do not provide a consensus due to methodologically weak empirical analysis. Therefore, fresh analyzes are required. As mentioned above, middle-income countries have the largest share in the world's agricultural production than other income groups. Especially in those countries that are in a transformation from agriculture to industry and the service sector, it is important to reveal the contribution of the development in the agricultural sector to economic growth in order to shape the policies to be implemented. In our study, empirically robust results with new panel data analysis methods are provided. Besides, since economic relations are often in a dynamic adjustment process (Bun \& Sarafidis, 2015), dynamic panel data estimators were used. 


\section{Methods}

In empirical studies in economic growth, economic growth is explained mainly by the expansion of the physical and human capital formation (Barro, 1991, 2001; Mankiw, Romer, \& Weil, 1992; Romer, 1989; Sala-i-Martin, 1997). Some studies provide evidence that trade openness has a positive impact on economic growth (Edwards, 1998; Frankel \& Romer, 1996; Sachs, Warner, Åslund, \& Fischer, 1995). Following the related literature, the estimated model in this study as follows;

$G D P_{i t}=\beta_{1 i}+\beta_{2} A G R_{i t}+\beta_{3} G C F_{i t}+\beta_{4} H C_{i t}+T R D_{i t}+\varepsilon_{i t}$

In equation 1, GDP is gross domestic product per capita (constant 2010 \$), GCF is gross capital formation percentage share of GDP, HC is human capital indicates average years of schooling based on the estimations of Barro and Lee (2013) and a rate of return to education based on the estimations of Psacharopoulos (1994). TRD is trade openness which refers to the sum of total exports and total imports percentage share of GDP. In the equation, AGR indicates agricultural productivity. Following Gardner (2005) and Tiffin and Irz (2006), agricultural value-added per worker (constant 2010 \$) was used as an indicator of agricultural labor productivity.

GDP, GCF, TRD, and AGR data are obtained from World Bank World Development Indicators (2019) while HC data from Penn World Tables (Feenstra, Inklaar, \& Timmer, 2015). Our dataset consists of data from 53 middle-income countries. ${ }^{1}$ The period is covering 1991-2017. All variables are turned into a logarithmic form. In the estimation of the model, second-generation panel data analysis methods were used.

\section{Cross-sectional Dependence and Slope Homogeneity}

Standard panel data analysis methods assume that no dependency exists between cross-section units and slope coefficients are homogenous. However, the estimators ignoring the cross-sectional dependence can result in misleading inference (Chudik \& Pesaran, 2013). In addition, the estimated coefficients may differ across cross-section units. Therefore, the existence of cross-sectional dependence and slope homogeneity will be investigated at first. The existence of cross-sectional dependence in the error term obtained from the model analyzed with Pesaran (2004) $C D_{L M}$ and Pesaran, Ullah, and Yamagata (2008) bias-adjusted $L M$ test. These methods are valid while $\mathrm{N}>\mathrm{T}$ and $\mathrm{T}>\mathrm{N}$. However, according to Pesaran (2004), there would be size distortions when $\mathrm{N}$ is relatively large. In our study, the time dimension is 27 , and the cross-section dimension is $53(\mathrm{~N}>\mathrm{T})$. Therefore, both $C D_{L M}$ and bias-adjusted $L M\left(L M_{a d j}\right)$ tests are used. Their test statistics can be calculated as follows:

$$
\begin{aligned}
& C D_{L M}=\left(\frac{1}{N(N-1)}\right)^{\frac{1}{2}} \sum_{i=1}^{N-1} \sum_{j=i+1}^{N}\left(T \hat{\rho}_{i j}^{2}-1\right) \\
& L M_{a d j}=\sqrt{\frac{2}{N(N-1)}} \sum_{i=1}^{N-1} \sum_{j=i+1}^{N} \frac{(T-k) \hat{\rho}_{i j}^{2}-\mu_{T i j}}{V_{T i j}}
\end{aligned}
$$

Equation 2 shows the calculation of Pesaran (2004) $C D_{L M}$ and equation 3 is Pesaran et al. (2008) bias-adjusted $L M$ test statistic. $V_{T i j}, \mu_{T i j}$, and $\hat{\rho}_{i j}$ respectively represent variance, mean, and the correlation between cross-section units. The null and alternative hypothesis for both test statistics; $H_{0}$ : No cross-sectional dependence exists

$H_{1}$ : Cross-sectional dependence exists

Pesaran and Yamagata (2008) developed Swamy's (1970) random coefficient model to investigate parameter heterogeneity in panel data analysis.

Swamy's test statistic can be calculated as follows.

\footnotetext{
1 Those countries are Albania, Argentina, Bangladesh, Belize, Bolivia, Botswana, Brazil, Bulgaria, Cameroon, China, Colombia, Congo, Costa Rica, Dominican Republic, Ecuador, Egypt, El Salvador, Eswatini, Gabon, Guatemala, Honduras, India, Indonesia, Iran, Jamaica, Jordan, Kenya, Kyrgyz Republic, Malaysia, Mauritania, Mauritius, Mexico, Mongolia, Morocco, Namibia, Nicaragua, Nigeria, Pakistan, Paraguay, Peru, Philippines, Romania, Russian Federation, Senegal, South Africa, Sri Lanka, Sudan, Thailand, Tunisia, Turkey, Ukraine, Vietnam, and Zimbabwe.
} 
$\hat{S}=\sum_{i=1}^{N}\left(\tilde{\beta}_{i}-\widetilde{\beta}_{W F E}\right) \frac{x_{i}^{\prime} M_{T} x_{i}}{\widetilde{\sigma}_{l}^{2}}\left(\tilde{\beta}_{i}-\widetilde{\beta}_{W F E}\right)(4)$

In equation $4, \tilde{\beta}_{i}$ and $\tilde{\beta}_{W F E}$ respectively indicate the parameters obtained from pooled OLS and weighted fixed effects estimation while $M_{T}$ is the identity matrix. Swamy's test statistic is developed by Pesaran et al. (2008) with the following equations,

$\tilde{\Delta}=\sqrt{N}\left(\frac{N^{-1} \tilde{S}-k}{\sqrt{2 k}}\right)$

$\tilde{\Delta}_{a d j}=\sqrt{N}\left(\frac{N^{-1} \tilde{S}-E\left(\tilde{Z}_{i t}\right)}{\sqrt{\operatorname{Var}\left(\tilde{Z}_{i t}\right)}}\right)$

where $\tilde{S}$ is the Swamy test statistic and k is the number of explanatory variables. $\tilde{\Delta}_{a d j}$ is a biasadjusted version of $\tilde{\Delta}$. $\tilde{Z}_{i t}=\mathrm{k}$ and $\operatorname{Var}\left(\tilde{Z}_{i t}\right)=2 k(T-k-1) / T+1$. The null and alternative hypothesis for both test statistics is given below.

$H_{0}: \beta_{i}=\beta$

$H_{1}: \beta_{i} \neq \beta$

The rejection of the null hypothesis shows the heterogeneity of slope coefficients in panel data models. After these preliminary analyses, stationarity levels of the variables will be examined with Pesaran's (2007) Cross-sectionally Augmented Dickey-Fuller (CADF) test.

\section{Unit Root Test}

Pesaran (2006) suggested a factor modeling approach that adds the cross-section averages as a proxy of unobserved common factors into the model to prevent the problems caused by crosssectional dependence. Following this approach, Pesaran (2007) proposed a unit root test. This method is based on augmenting the Augmented Dickey-Fuller (ADF) regression with lagged crosssectional mean and its first difference to deal with cross-sectional dependence (Baltagi, 2008). This method considers the cross-sectional dependence and can be used while $\mathrm{N}>\mathrm{T}$ and $\mathrm{T}>\mathrm{N}$. The $\mathrm{CADF}$ regression is;

$\Delta y_{i t}=\alpha_{i}+\rho_{i}^{*} y_{i, t-1}+d_{0} \bar{y}_{t-1}+d_{1} \Delta \bar{y}_{t}+\epsilon_{i t}$

$\bar{y}_{t}$ is the average of all $\mathrm{N}$ observations. To prevent serial correlation, the regression must be augmented with lagged first differences of both $y_{i t}$ and $\bar{y}_{t}$ as follows;

$\Delta y_{i t}=\alpha_{i}+\rho_{i}^{*} y_{i, t-1}+d_{0} \bar{y}_{t-1}+\sum_{j=0}^{p} d_{j+1} \Delta \bar{y}_{t-j}+\sum_{k=1}^{p} c_{k} \Delta y_{i, t-k}+\epsilon_{i t}$

After this, Pesaran (2007) averages the t statistics of each cross-section unit $\left(C A D F_{i}\right)$ in the panel and calculates CIPS statistic as follows;

CIPS $=\frac{1}{N} \sum_{i=1}^{N} C A D F_{i}$

The null hypothesis of this test is the existence of a unit root in the panel in question. After the preliminary analysis of unit root, the long-run relationship will be investigated via Westerlund's (2008) Durbin-Hausman cointegration test and Dynamic CCEMG (Dynamic Common Correlated Effects Mean Group) estimator developed by Chudik and Pesaran (2015).

\section{Cointegration and Long-Run Estimation}

In our study, we investigate the cointegration relationship between the variables using the DurbinHausman test developed by Westerlund (2008). Cross-section dependence is allowed by modeling common factors by fitting the error term obtained from equation $1\left(\varepsilon_{i t}\right)$ to the following set of equations.

$$
\begin{aligned}
& \varepsilon_{i t}=\lambda_{i}^{\prime} F_{t}+e_{i t} \\
& F_{j t}=\rho_{j} F_{j t-1}+u_{j t}
\end{aligned}
$$


$e_{i t}=\phi_{i} e_{i t-1}+v_{i t}$

In equation $10, F_{t}$ is a $k$ dimensional vector of common factors $F_{j t}(j=1, \ldots, k)$, while $\lambda_{i}$ is a vector of factor loadings. Under the assumption of $\rho_{j}<1$ for all $j, F_{t}$ is stationary. Therefore, the integration order of $\varepsilon_{i t}$ depends only on the integratedness of $e_{i t}$. Consequently, there is a cointegration when $\phi_{i}<1$. This method allows different orders of stationarity to examine the cointegration relationship. However, the only requirement is that the dependent variable is nonstationary (Westerlund, 2008: 205). The author suggested two different test statistics as shown in the following equations.

$D H_{g}=\sum_{i=1}^{n} \hat{S}_{i}\left(\tilde{\phi}_{i}-\hat{\phi}_{i}\right)^{2} \sum_{t=2}^{T} \hat{e}_{i t-1}^{2}$
$D H_{p}=\hat{S}_{n}\left(\tilde{\phi}_{i}-\hat{\phi}_{i}\right)^{2} \sum_{i=1}^{n} \sum_{t=2}^{T} \hat{e}_{i t-1}^{2}$

The panel statistic $\left(D H_{p}\right)$ assumes parameter homogeneity and the group statistic $\left(D H_{g}\right)$ assumes parameter heterogeneity. If the calculated test statistics are above the critical value, the null of "no cointegration" will be rejected.

The CCEMG estimation method is also based on the factor modeling approach. It is an estimation method that is adding cross-section averages to the model as common factors. Pesaran (2006) suggested two estimation methods in his work. The first is CCEMG (Common Correlated Effects Mean Group), and the second one is CCEP (Common Correlated Effects Pooled), while CCEMG assumes parameter heterogeneity and CCEP parameter homogeneity. After the preliminary analysis of slope homogeneity, CCEMG estimation was found appropriate for our analysis. This method considers the cross-sectional dependency, slope heterogeneity, and nonstationarity (Eberhardt, 2012). CCEMG estimator is based on the following equation.

$\hat{b}_{i}=\left(X_{i}^{\prime} M_{w} X_{i}\right)^{-1} X_{i}^{\prime} M_{w}^{*} Y_{i}$

$\hat{b}_{C C E M G}=\frac{1}{N} \sum_{i=1}^{N} \hat{b}_{i}$

where $\hat{b}_{i}$ denotes individual CCE estimation for each cross-section unit. After the calculation of $\hat{b}_{i} \hat{b}_{C C E M G}$ will be calculated by taking the average of slopes calculated for each unit. Pesaran (2006) stated that this estimator yields more effective results than the estimators that do not consider cross-sectional dependence. In addition, Chudik and Pesaran (2015) developed the dynamic version of the CCEMG estimator. This estimator is based on the idea that augmenting the CCEMG estimator with a lagged dependent variable as follows

$y_{i t}=\lambda_{i} y_{i, t-l}+\beta_{i} x_{i, t}+\sum_{l=0}^{p_{T}} \varphi_{i, l}^{\prime} \bar{z}_{i, t-l}+\varepsilon_{i t}$

where $\bar{z}_{t-l}$ refers to lagged cross-sectional averages $\left[\bar{z}_{t}=\left(\bar{y}_{t}, \bar{x}_{t}\right)\right]$. The model with a lagged dependent variable is no more strictly exogenous. Chudik and Pesaran (2015) proposed that adding lagged cross-sectional averages mitigates the endogeneity problem. However, the authors also showed a negative bias in CCEMG estimation with a lagged dependent variable when $\mathrm{T}<50$. To prevent small sample time series bias, Chudik and Pesaran (2015) suggested two different methods. The first is the split-panel jackknife method developed by Dhaene and Jochmans (2015). The second is the recursive mean adjustment method developed by So and Shin (1999). The jackknife method is based on the following equation.

$\tilde{\pi}_{M G}=2 \tilde{\pi}_{M G}-1 / 2\left(\hat{\pi}_{M G}^{a}+\hat{\pi}_{M G}^{b}\right)$

In equation $18, \hat{\pi}_{M G}^{a}$ denotes the CCEMG estimation with the first half of time dimension $(t=1,2,3$, $\ldots,(\mathrm{T} / 2))$ and $\hat{\pi}_{M G}^{b}$ denotes estimation with second half of time dimension $(\mathrm{t}=(\mathrm{T} / 2)+1,(\mathrm{~T} / 2)+2, \ldots$, T). Bias correction of CCEMG estimator with recursive mean adjustment method is as simple as the jackknife method. It is based on the de-meaning of the variables. According to So and Shin (1999), using the partial mean of variables is not influenced by future observations. Chudik and Pesaran (2015) revealed that the jackknife method outperforms the recursive mean adjustment method. Therefore, in our study, we used the jackknife method to prevent small sample time series bias. 


\section{Results and Discussion}

The results obtained from Pesaran (2004) $C D_{L M}$ and Pesaran et al. (2008) bias-adjusted LM ( $\left.L M_{a d j}\right)$ cross-sectional dependence tests and Pesaran and Yamagata (2008) slope homogeneity tests are given in table 2 .

Table 2. Cross-sectional Dependence and Slope Homogeneity Results

\begin{tabular}{lll}
\hline Test & Statistics & p-value \\
\hline $\mathrm{CD}_{\mathrm{LM}}$ & 9.125 & 0.000 \\
$\mathrm{LM}_{\text {adj }}$ & 59.9 & 0.000 \\
$\tilde{\Delta}$ & 70.522 & 0.000 \\
$\tilde{\Delta}_{\text {adj }}$ & 75.676 & 0.000 \\
\hline
\end{tabular}

According to the results, the null hypotheses of cross-sectional independence are rejected at $1 \%$ significance level. The presence of cross-sectional dependency in the model indicates that there is a significant correlation between the error terms obtained for each cross-section unit. As stated earlier, using estimation methods that do not take this effect into account cause biased and inconsistent results. In addition, the results of slope homogeneity tests indicate that the null of homogeneity is rejected at $1 \%$. This result indicates that the estimated slope parameters differ between the countries included in the analysis. In other words, the slope parameters are heterogeneous. Within the framework of this result, mean group estimators that make individual estimates for each cross-section included in the panel should be used. The CADF unit root test developed by Pesaran (2007)) is robust under cross-sectional dependency and slope heterogeneity. The results are given in Table 3.

Table 3. CADF Unit Root Test Results

\begin{tabular}{llll}
\hline & Level & $1^{\text {st }}$ difference & Results \\
\cline { 2 - 4 } GDP & -2.179 & $-3.794^{* * *}$ & $I_{1}$ \\
AGR & $-2.862^{* * *}$ & - & $I_{0}$ \\
GCF & $-2.678^{* *}$ & - & $I_{0}$ \\
HC & -2.054 & $-2.230^{* *}$ & $I_{1}$ \\
TRD & -2.308 & $-2.752^{* * *}$ & $I_{1}$ \\
\hline
\end{tabular}

***, $* *$ indicates rejection of the null hypothesis at $5 \%$ and $1 \%$ level respectively. The critical value for the model with constant and trend at $1 \%$ is -2.780 while it is -2.30 for the model with constant only. The critical value for $\% 5$ significance level for the model with constant and trend is -2.65 and for the model with constant only is -2.15 .

In the unit root analysis, maximum lag is determined as 3 , and optimum lag level is determined by $\mathrm{F}$ joint test from general to particular. While the variables are at level, the constant and trend are considered together. Only the constant is considered while the variables are first differenced. The results show that GDP, HC, and TRD variables are nonstationary at level, but their first differences are stationary. Also, AGR and GCF variables are trend stationery. These results indicate that the variables are integrated into different orders.

Our preliminary analysis shows that our variables are cross-sectionally dependent, and the slope coefficients are heterogeneous. Within the framework of these results, methods that yield robust results with variables at different orders of stationarity should be used while making cointegration analysis and long-run estimation. According to Westerlund (2008), the DurbinHausman cointegration method can be used while variables are integrated with different orders as long as the dependent variable is $I_{1}$. In estimating long-run coefficients, the CCEMG method proposed by Pesaran (2006) was found appropriate. The CCEMG estimator provides robust results under cross-sectional dependence, and it assumes heterogeneous slopes. It is also robust regardless of the integration levels of the variables (Eberhardt, 2012). The results of the Durbin-Hausman cointegration test are given in Table 4. 
Table 4. Durbin-Hausman Cointegration Results

\begin{tabular}{ll}
\hline $\mathrm{D}-\mathrm{H}$ group statistic & $\mathrm{p}$-value \\
\hline-1.703 & 0.044 \\
\hline
\end{tabular}

In the cointegration analysis, the maximum lag level selected as 3, and optimum lag is determined by the Akaike Information Criterion. The constant term is also included in the model, and the maximum number of common factors determined as 3 . Due to the results of homogeneity tests we performed, we consider the Durbin-Hausman group statistic that assumes slope heterogeneity. The results indicate that the null of no cointegration is rejected at $\% 5$ significance level. There is a significant long-run relationship between those variables.

After the cointegration analysis, the long-run coefficients are estimated via the CCEMG estimator. We also reported the Dynamic CCEMG estimation results and its bias-corrected form with a split-panel jackknife $\left(C C E M G_{J K}\right)$ method. As Baltagi (2008) stated, most of the economic relations have a naturally dynamic structure, and a lagged value of the dependent variable should be among the explanatory variables in the estimation of these relations. However, a long period is required $(\mathrm{T}>50)$ for the Dynamic-CCEMG estimator to give unbiased results (Chudik \& Pesaran, 2013). Therefore, the estimation results corrected by the half-panel Jackknife method suggested by Chudik and Pesaran (2015) are considered to be the most appropriate results. The results are given in Table 5.

Table 5. Long-Run Estimation Results

\begin{tabular}{|c|c|c|c|}
\hline & CCEMG & Dynamic CCEMG & Dynamic CCEMG $G_{J K}$ \\
\hline $\operatorname{GDP}(-1)$ & & $0.383(9.83)^{* * *}$ & $0.405(7.89)^{* * *}$ \\
\hline AGR & $0.116(3.65)^{* * *}$ & $0.082(4.22)^{* * *}$ & $0.074(3.11)^{* * *}$ \\
\hline GCF & $0.146(6.96)^{* * *}$ & $0.088(4.98)^{* * *}$ & $0.097(4.73)^{* * *}$ \\
\hline $\mathrm{HC}$ & $0.444(1.85)^{*}$ & $1.245(1.98)^{* *}$ & $2.515(2.91)^{* * *}$ \\
\hline TRD & $-0.023(-1.00)$ & $-0.009(-0.59)$ & $-0.003(-0.19)$ \\
\hline $\mathrm{C}$ & $0.814(1.23)$ & $1.037(1.20)$ & $0.877(0.89)$ \\
\hline
\end{tabular}
in parenthesis.

In the estimation of Dynamic CCEMG, lagged cross-sectional averages are added, and lag structure is determined as 2. According to the results of CCEMG estimation, agricultural productivity has a positive impact which is significant at $1 \%$ on GDP per capita growth. A $1 \%$ increase in agricultural productivity increases GDP per capita by $0.11 \%$. The Dynamic CCEMG estimation and its bias-corrected version with the jackknife method are supporting the CCEMG results. A 1\% increase in agricultural productivity increases GDP per capita by about $0.08 \%$. Our results that agricultural production is one of the engines of economic growth, supporting the results of Hwa (1988), Tiffin and Irz (2006), and Yao (2000). The contribution of agricultural productivity to economic growth is strongly significant. Efforts to increase labor productivity in agriculture provide more labor input for the industrial sector while also creating an increase in demand for agricultural machinery and equipment produced by the industrial sector (Khan et al., 2020). It also increases foreign exchange earnings via rising agricultural exports. At the same time, it is necessary to increase agricultural productivity in order to feed the population employed in the industrial sector (Matsuyama, 1992). Contrary to development theories that exclude efforts to increase productivity in agriculture (Timmer, 2002) and agriculture's lower education demand compared to other sectors (Gylfason, 2000), it is seen that increasing the value of agricultural output per worker has a positive effect on the overall economic growth.

Gross capital formation is also having a positive and significant impact on economic growth at $1 \%$ level. An increase in capital formation leads to a $0.14 \%$ increase in economic growth, while dynamic estimation and bias-corrected estimation results show that its effect is $0.08 \%$ and $0.09 \%$, respectively. Savings and investments have been seen as the main source of economic growth since the standard Neoclassical models (Solow, 1956). Human capital is also estimated as another control 
variable. Mankiw et al. (1992) argued that human capital should be taken into account in addition to physical capital while explaining the growth differences between countries. Supportively, our results indicate that human capital is another determinant of economic growth. CCEMG estimation shows that a $1 \%$ increase in the human capital index leads to an increase in GDP per capita by $0.44 \%$, which is significant at $10 \%$. The dynamic estimation results also show that the effect of human capital is positive but significant at $5 \%$ while the significance is $1 \%$ in biascorrected estimation. Human capital formation is an important instrument for developing economies to catch up with developed economies. A high level of human capital provides a more successful and, therefore, more productive workforce in creating and implementing new technologies (Benhabib \& Spiegel, 1994). According to Barro (2001), higher levels of human capital lead to lower fertility and higher investment ratios to GDP. Our results about physical and human capital formation also support the evidence of Romer (1989) and Sala-i-Martin (1997). The effect of trade openness on economic growth is the opposite of the expected. No significant relationship was found, and this result does not support the evidence of Edwards (1998), Frankel and Romer (1996), and Sachs et al. (1995) in which the authors found a significant positive impact of trade openness on economic growth.

\section{Conclusion}

In this study, the role of agriculture in economic growth is investigated with annual data of 53 middle-income countries in the period 1991-2017. As a methodological contribution to previous studies, the second-generation panel data analysis methods, which consider cross-sectional dependency, were used. First, the stationarity properties of the variables are tested with the CADF unit root test. The results show the variables are stationary in different orders. Therefore, the Durbin-Hausman cointegration test that allows different orders of stationarity was used to determine the existence of a long-run relationship. According to the Durbin-Hausman cointegration test results, there is a significant long-run relationship between economic growth, agricultural productivity, trade openness, human capital, and gross capital formation. After that, long-run coefficients are estimated via CCEMG and Dynamic CCEMG estimator. In addition, the split-panel jackknife bias correction method is used in order to deal with the small sample time series bias. The results show that agricultural growth is positively associated with overall economic growth according to CCEMG, Dynamic CCEMG, and bias-corrected CCEMG estimations. These results do not support the view that there is no need for efforts to increase productivity in agriculture as the share of agriculture in national income will naturally decrease over time. In addition to industrialization efforts, developing countries will be able to accelerate their economic growth through investments that increase productivity in agriculture. In addition to the main findings, gross capital formation and human capital also positively affect economic growth. No significant relationship was found between trade openness and economic growth.

The middle-income countries have not yet fully succeeded in their expected transformation from agriculture to industry. Naturally, there is an effort for industrialization to achieve a higher income level. However, this study shows that necessary attention should be paid to the development of the agricultural sector, just as in the industrialization to reach high income. In developing economies where agricultural production still plays an important role in economic growth, policymakers should encourage the use of technology in agriculture (Mariyono, 2009). As stated by Gardner (2005) and in the studies on production theory, the way to increase output per worker will be possible mainly by technological development and human capital investments. There is a significant difference in the context of agricultural productivity between high and middleincome countries. To cover this gap, the use of more modern methods in agriculture should be encouraged, primitive methods that are climate-dependent should be abandoned, and more resources should be allocated to agricultural research and development activities. The policymakers should provide incentives to increase infrastructure investments and transport facilities in rural areas. Besides, training opportunities should be provided to meet the need for well-educated people in agriculture to improve worker's skills. Such efforts to increase agricultural productivity may 
increase economic growth rates in middle-income countries. The diminishing share of agriculture in GDP and the re-allocation of workers may be good for industrial development when this reallocation process is supported with productivity increases in the agricultural sector (Gollin et al., 2002). It is a transformation process from labor-intensive to technology-intensive production in the agricultural sector. With this transformation, countries may benefit from the positive effects of agriculture in the context of both industrial development and food production.

\section{References}

Awokuse, T. O., \& Xie, R. (2015). Does agriculture really matter for economic growth in developing countries? Canadian Journal of Agricultural Economics/Revue Canadienne d'agroeconomie, 63(1), 77-99. https://doi.org/10.1111/cjag.12038

Baltagi, B. (2008). Econometric analysis of panel data. Chichester: John Wiley \& Sons Ltd.

Barro, R. J. (1991). Economic growth in a cross section of countries. The Quarterly Journal of Economics, 106(2), 407-443. https://doi.org/10.2307/2937943

Barro, R. J. (2001). Human capital and growth. The American Economic Review, 91(2), 12-17. https://doi.org/10.1257/aer.91.2.12

Barro, R. J., \& Lee, J. W. (2013). A new data set of educational attainment in the world, 19502010. Journal of Development Economics, 104, 184-198. https://doi.org/10.1016/j.jdeveco.2012.10.001

Beintema, N., Stads, G. J., Fuglie, K., \& Heisey, P. (2012). ASTI global assessment of agricultural R\&D spending: Developing countries accelerate investment. Washington, DC.

Benhabib, J., \& Spiegel, M. M. (1994). The role of human capital in economic development evidence from aggregate cross-country data. Journal of Monetary Economics, 34(2), 143-173. https://doi.org/10.1016/0304-3932(94)90047-7

Bravo-Ortega, C., \& Lederman, D. (2005). Agriculture and national welfare around the world: Causality and international heterogeneity since 1960 (World Bank Policy Research Working Paper No. 3499).

Bun, M. J., \& Sarafidis, V. (2015). Dynamic panel data models. In The Oxford handbook of panel data (pp. 76-110).

Chebbi, H. E. (2010). Agriculture and economic growth in Tunisia. China Agricultural Economic Review, 2(1), 63-78. https://doi.org/10.1108/17561371011017504

Chudik, A., \& Pesaran, M. H. (2013). Large panel data models with cross-sectional dependence: A survey (Federal Reserve Bank of Dallas Globalization and Monetary Policy Institute Working Paper No. 153).

Chudik, A., \& Pesaran, M. H. (2015). Common correlated effects estimation of heterogeneous dynamic panel data models with weakly exogenous regressors. Journal of Econometrics, 188(2), 393-420. https://doi.org/10.1016/j.jeconom.2015.03.007

De Hoyos, R., \& Sarafidis, V. (2006). Testing for cross-sectional dependence in panel-data models. The Stata Journal, 6(4), 482-496. https://doi.org/10.1177/1536867X0600600403

Dhaene, G., \& Jochmans, K. (2015). Split-panel jackknife estimation of fixed-effect models. The Review of Economic Studies, 82(3), 991-1030. https://doi.org/10.1093/restud/rdv007

Eberhardt, M. (2012). Estimating panel time-series models with heterogeneous slopes. Stata Journal, 12(1), 61-71. https://doi.org/10.1177/1536867X1201200105

Edwards, S. (1998). Openness, productivity and growth: What do we really know? The Economic Journal, 108(447), 383-398. https://doi.org/10.1111/1468-0297.00293 
FAO. (2018). World food and agriculture - Statistical pocketbook 2018. Retrieved from http://www.fao.org/publications/card/en/c/CA1796EN/

Feenstra, R. C., Inklaar, R., \& Timmer, M. P. (2015). The next generation of the penn world table. American Economic Review, American Economic Association, 105(10), 3150-3182. https://doi.org/10.1257/aer.20130954

Frankel, J., \& Romer, D. (1996). Trade and growth: An empirical investigation (NBER Working Papers No. 5476).

Gardner, B. L. (2005). Causes of rural economic development. Agricultural Economics, 32(s1), 2141. https://doi.org/10.1111/j.0169-5150.2004.00012.x

Ghatak, S., \& Ingersent, K. (1984). Agriculture and economic development. Baltimore, Meryland.: The John Hopkins University Press.

Gollin, D., Parente, S., \& Rogerson, R. (2002). The role of agriculture in development. American Economic Review, 92(2), 160-164. https://doi.org/10.1257/000282802320189177

Gylfason, T. (2000). Resources, agriculture and economic growth in economies in transition (CESifo Working Paper No. 313).

Hirschman, A. O. (1958). The strategy of economic development. New Haven: Yale University Press.

Hwa, E. C. (1988). The contribution of agriculture to economic growth: Some empirical evidence. World Development, 16(11), 1329-1339. https://doi.org/10.1016/0305750X(88)90208-2

Irz, X., Lin, L., Thirtle, C., \& Wiggins, S. (2001). Agricultural productivity growth and poverty alleviation. Development Policy Review, 19(4), 449-466. https://doi.org/10.1111/14677679.00144

Johnston, B. F., \& Mellor, J. W. (1961). The role of agriculture in economic development. The American Economic Review, 51(4), 566-593.

Katircioglu, S. T. (2006). Causality between agriculture and economic growth in a small nation under political isolation: A case from North Cyprus. International Journal of Social Economics, 33(4), 331-343.

Khan, W., Jamshed, M., \& Fatima, S. (2020). Contribution of agriculture in economic growth: A case study of West Bengal (India). Journal of Public Affairs, 20(2), 1-10. https://doi.org/10.1002/pa.2031

Kuznets, S. (1964). Economic growth and the contribution of agriculture. In C. K. Eicher \& Witt (Eds.), Agriculture in Economic Development. New York: McGraw-Hill.

Lewis, W. A. (1954). Economic development with unlimited supplies of labour. The Manchester School, 22(2), 139-191. https://doi.org/10.1111/j.1467-9957.1954.tb00021.x

Mankiw, N. G., Romer, D., \& Weil, D. N. (1992). A contribution to the empirics of economic growth. The Quarterly Journal of Economics, 107(2), 407-437. https://doi.org/10.2307/2118477

Mariyono, J. (2009). Technological bias in Indonesian rice production: Why does agrochemical use increase over time? Quarterly Journal of International Agriculture, 48(1), 47.

Mariyono, J. (2019). Micro-credit as catalyst for improving rural livelihoods through agribusiness sector in Indonesia. Journal of Entrepreneurship in Emerging Economies, 11(1), 98-121. https://doi.org/10.1108/jeee-06-2017-0046

Mariyono, J., Kompas, T., \& Grafton, R. Q. (2010). Shifting from Green Revolution to environmentally sound policies: Technological change in Indonesian rice agriculture. Journal of the Asia Pacific Economy, 15(2), 128-147. 
https://doi.org/10.1080/13547861003700109

Matsuyama, K. (1992). Agricultural productivity, comparative advantage, and economic growth. Journal of Economic Theory, 58(2), 317-334. https://doi.org/10.1016/0022-0531(92)90057$\mathrm{O}$

Menyah, K., Nazlioglu, S., \& Wolde-Rufael, Y. (2014). Financial development, trade openness and economic growth in African countries: New insights from a panel causality approach. Economic Modelling, 37, 386-394. https://doi.org/10.1016/j.econmod.2013.11.044

Nicholls, W. H. (1964). Agricultural policy: The place of agriculture in economic development. In Economic Development with Special Reference to East Asia (pp. 336-375). London: Palgrave Macmillan.

Oyakhilomen, O., \& Zibah, R. G. (2014). Agricultural production and economic growth in Nigeria: Implication for rural poverty alleviation. Quarterly Journal of International Agriculture, 53(3), 207-223. https://doi.org/10.22004/ag.econ.195735

Pesaran, M. H. (2004). General diagnostic tests for cross-section dependence in panels (CESifo Working Paper No. 1229).

Pesaran, M. H. (2006). Estimation and inference in large heterogeneous panels with a multifactor error structure. Econometrica, 74(4), 967-1012. https://doi.org/10.1111/j.14680262.2006.00692.x

Pesaran, M. H. (2007). A simple panel unit root test in the presence of cross-section dependence. Journal of Applied Econometrics, 22(2), 265-312. https://doi.org/10.1002/jae.951

Pesaran, M. H., Ullah, A., \& Yamagata, T. (2008). A bias-adjusted LM test of error cross-section independence. The Econometrics Journal, 11(1), 105-127. https://doi.org/10.1111/j.1368423X.2007.00227.x

Pesaran, M. H., \& Yamagata, T. (2008). Testing slope homogeneity in large panels. Journal of Econometrics, 142(1), 50-93. https://doi.org/10.1016/j.jeconom.2007.05.010

Prebisch, R. (1950). The economic development of Latin America and its principal problems. U.N. Department of Economic Affairs.

Psacharopoulos, G. (1994). Returns to investment in education: A global update. World Development, 22(9), 1325-1343. https://doi.org/10.1016/0305-750X(94)90007-8

Romer, P. M. (1989). Human capital and growth: Theory and evidence (No. w3173).

Sachs, J. D., Warner, A., Åslund, A., \& Fischer, S. (1995). Economic reform and the process of global integration. Brookings Papers on Economic Activity, 26(1), 1-118.

Sala-i-Martin, X. X. (1997). I just ran four million regressions (National Bureau of Economic Research. No. w6252).

Sertoglu, K., Ugural, S., \& Bekun, F. V. (2017). The contribution of agricultural sector on economic growth of Nigeria. International Journal of Economics and Financial Issues, 7(1), 547 552.

So, B. S., \& Shin, D. W. (1999). Recursive mean adjustment in time-series inferences. Statistics \& Probability Letters, 43(1), 65-73. https://doi.org/10.1016/S0167-7152(98)00247-8

Solow, R. M. (1956). A contribution to the theory of economic growth. The Quarterly Journal of Economics, 70(1), 65-94. https://doi.org/10.2307/1884513

Swamy, P. A. (1970). Efficient inference in a random coefficient regression model. Econometrica: Journal of the Econometric Society, 38(2), 311-323. https://doi.org/10.2307/1913012

Tiffin, R., \& Irz, X. (2006). Is agriculture the engine of growth? Agricultural Economics, 35(1), 79 
89. https://doi.org/10.1111/j.1574-0862.2006.00141.x

Timmer, C. P. (1995). Getting agriculture moving: Do markets provide the right signals? Food Policy, 20(5), 455-472. https://doi.org/10.1016/0306-9192(95)00038-G

Timmer, C. P. (2002). Agriculture and economic development. In Handbook of agricultural economics (2nd ed., pp. 1487-1546).

Tsakok, I., \& Gardner, B. (2007). Agriculture in economic development: Primary engine of growth or chicken and egg? American Journal of Agricultural Economics, 89(5), 1145-1151. https://doi.org/10.1111/j.1467-8276.2007.01075.x

Westerlund, J. (2008). Panel cointegration tests of the Fisher effect. Journal of Applied Econometrics, 23(2), 193-233. https://doi.org/10.1002/jae.967

World Bank. (2019). World Development Indicators. Washington. Retrieved from https://datatopics.worldbank.org/world-development-indicators/

Yao, S. (2000). How important is agriculture in China's economic growth? Oxford Development Studies, 28(1), 33-49. https://doi.org/10.1080/713688306 